
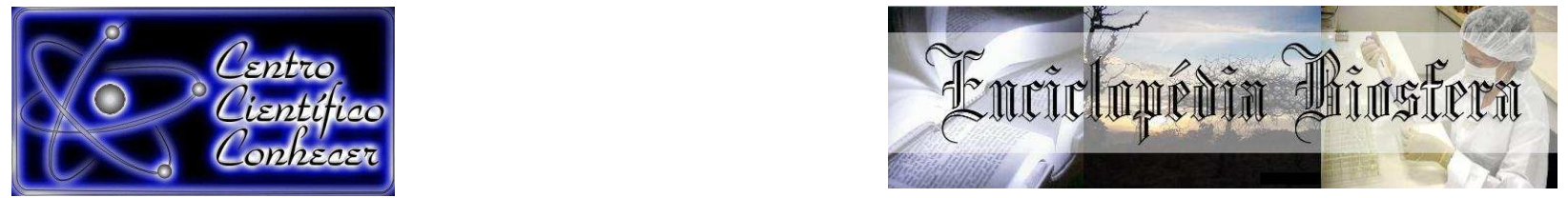

\title{
QUALIDADE SANITÁRIA E FISIOLÓGICA DE SEMENTES DE CHIA
}

Tainan Lopes de Almeida ${ }^{1}$, Daniele Brandstetter Rodrigues ${ }^{2^{*}}$, Thaís D'Avila Rosa ${ }^{2}$, Gabriela Berguenmaier de Olanda ${ }^{3}$, Candida Renata Jacobsen de Farias ${ }^{4}$

1 Mestrando do PPG em Ciência e Tecnologia de Sementes da Universidade Federal de Pelotas (tainanalmeida.92@hotmail.com) Pelotas, RS, Brasil.

2 Doutoranda do PPG em Ciência e Tecnologia de Sementes da Universidade Federal de Pelotas. Pelotas, RS, Brasil.

3 Doutoranda do PPG em Sistemas de Produção Agrícola Familiar da Universidade Federal de Pelotas. Pelotas, RS, Brasil.

4 Professora Doutora, Faculdade de Agronomia Eliseu Maciel, Universidade Federal de Pelotas. Pelotas, RS, Brasil.

Recebido em: 08/04/2016 - Aprovado em: 30/05/2016 - Publicado em: 20/06/2016 DOI: 10.18677/Enciclopedia_Biosfera_2016_096

Com o objetivo de avaliar a incidência fúngica e a qualidade fisiológica de sementes chia (Salvia hispanica L.), foram analisados seis lotes de sementes da espécie, provenientes do mercado local do município de Pelotas- RS, Brasil. Para a análise sanitária o método utilizado foi o "Blotter Test" e para o teste da qualidade fisiológica o teste de germinação e índice de velocidade de emergência (IVG). Os resultados obtidos permitiram constatar que os Lotes 3 e 5 não apresentaram incidência de fungos e nos demais evidenciou-se a presença de Aspergillus sp., Cladosporium sp., Bipolaris sp., e Fusarium sp. Sementes de chia disponíveis no comércio do município de Pelotas-RS apresentam baixa incidência de fungos fitopatogênicos, porém há variação na qualidade fisiológica.

PALAVRAS CHAVE: fungos, germinação, Salvia hispanica L.

\section{HEALTH AND PHYSIOLOGICAL QUALITY OF SEEDS OF CHIA}

\begin{abstract}
In order to assess the fungal incidence and physiological quality of chia seeds (Salvia hispanica L.) were analyzed six seed lots of the species, from the local market in the municipality of Pelotas, Brazil. For health analysis method used was the "Blotter Test" and for testing the physiological quality germination test and emergence speed index. The results revealed that Lots 3 and 5 showed no incidence of fungi and the other showed the presence of Aspergillus sp., Cladosporium sp., Bipolaris sp. and Fusarium sp. Chia seeds available in the trade of the municipality of Pelotas-RS present low incidence of phytopathogenic fungi, however there are variation in physiological quality.
\end{abstract}

KEYWORDS: fungi, germination, Salvia hispanica L.. 


\section{INTRODUÇÃO}

A chia (Salvia hispanica L.) é uma planta herbácea anual, a qual faz parte à família Lamiaceae, O cultivo é realizado do oeste Mexicano até o norte da Guatemala. As tribos astecas utilizavam as sementes de chia como alimento (como sementes inteiras, farinhas, mucilagem ou óleo), medicamento e na fabricação de tintas. Atualmente, o cultivo da espécie concentra-se nos países do México, Bolívia, Equador e Guatemala (OLIVOS-LUGO et al., 2010; MARTINEZ et al., 2012).

As sementes de chia possuem elevado teor de ácidos graxos com evidência para os essenciais ao ser humano, como o ácido alfa linolênico (ômega 3) e ácido linoleico (ômega 6). Além disso, esta espécie é uma excelente fonte de fibra dietética, definindo-se como um alimento benéfico ao metabolismo humano, principalmente quanto à sua capacidade de redução do risco de doenças do trato gastrointestinal, de doenças cardiovasculares e dos níveis de colesterol no sangue (COATES, 2012).

A propagação da cultura da chia se dá especialmente por sementes, portanto a qualidade sanitária é um fator de grande relevância a sua produção, pois sementes contaminadas são veículos de disseminação de patógenos, principalmente fungos (BARROCAS \& MACHADO, 2010).

O potencial fisiológico é um fator bastante importante, pois abrange informações sobre a germinação (viabilidade) e o vigor de sementes. A avaliação da qualidade fisiológica de possibilita a identificação de lotes de sementes que possuem potencial elevado de apresentar o desempenho esperado durante 0 armazenamento e também em campo (MARCOS FILHO, 2013). Diante do exposto, objetivou-se estimar o potencial fisiológico e sanitário de sementes de chia.

\section{MATERIAL E MÉTODOS}

Foram utilizadas sementes de seis lotes de chia (Salvia hispanica L.) provenientes do comércio local de Pelotas- RS, Brasil, adquiridas em porções de 300 gramas cada lote, realizando as posteriores análises, no ano de 2015. O delineamento experimental foi o inteiramente ao acaso.

A avaliação da incidência dos fungos fitopatogênicos ocorreu por meio da incubação das sementes pelo método "Blotter Test" (BRASIL, 2009). Utilizaram-se quatro repetições de 50 sementes por caixa gerbox, para cada lote. As sementes foram dispostas a um $\mathrm{cm}$ uma das outras sobre duas folhas de papel mata borrão, previamente umedecido 2,5 vezes a massa do papel com água destilada nas caixas gerbox.

As sementes permaneceram por 24 horas em sala de incubação com temperatura de $22^{\circ} \mathrm{C}$ e fotoperíodo de 12 horas. Em s eguida, foram transferidas para um frezzer com temperatura de $-20^{\circ} \mathrm{C}$, onde permanec eram por mais 24 horas e posteriormente retornaram para a sala de incubação, por um período de sete. Ao término, com auxílio de microscópio esteroscópio, foi efetuada a avaliação da presença dos gêneros de fungos associados às sementes, sendo observado características morfológicas do sistema vegetativo e reprodutivo. Sempre que necessário procedeu-se laminas microscópicas para visualização mais detalhada das características relevantes para cada gênero. Os resultados foram expressos em porcentagem de fungos.

Para o teste de germinação foram utilizadas quatro repetições de 50 sementes para cada lote, acondicionadas em caixas do tipo gerbox, com papel mata borrão umedecido com água destilada 2,5 vezes a sua massa e mantidas em 
câmara de germinação tipo BOD, a uma temperatura de $25^{\circ} \mathrm{C}$. A avaliação da germinação foi realizada aos sete dias transcorridos após a montagem do teste, considerando número de plântulas normais.

O índice de velocidade de germinação foi realizado concomitantemente com o teste de germinação, considerando-se a protusão da radícula. Utilizaram-se quatro repetições de 50 sementes para cada lote, acondicionadas em caixas do tipo gerbox, com papel mata borrão umedecido com água destilada 2,5 vezes a sua massa e mantidas em câmara de germinação tipo BOD, a uma temperatura de $25^{\circ} \mathrm{C}$. A partir da contagem diária das sementes germinadas determinou-se o índice de velocidade de germinação por meio da seguinte fórmula:

$$
\mathrm{IVG}=(\mathrm{N} 1 / \mathrm{G} 1+\mathrm{N} 2 / \mathrm{G} 2+\mathrm{Nn} / \mathrm{Gn})
$$

Onde:

"IVG" índice de velocidade de germinação.

"N" número de sementes germinadas no dia.

"G" tempo em dias.

A significância do efeito dos lotes foi determinada por meio do Teste $F$, sendo as médias comparadas por meio do Teste de Tukey $(\mathrm{p}<0,05)$.

\section{RESULTADOS E DISCUSSÃO}

Por meio da análise sanitária de sementes de chia, verificou-se que apenas os Lotes 3 e 4 não apresentaram incidência de fungos sendo que nos demais foram observadas a presenças dos fungos Aspergillus sp., Cladosporium sp., Bipolaris sp. e Fusarium sp. (Tabela 1).

TABELA 1- Ocorrência de fungos em sementes de chia, de diferentes lotes provenientes do município de Pelotas.

\begin{tabular}{ccc}
\hline Lotes & Fungos & $\%$ \\
\hline Lote 1 & Aspergillus sp. & 0,5 \\
Lote 2 & Cladosporium sp. & 1 \\
Lote 3 & - & \\
Lote 4 & Bipolaris sp. & 1 \\
Lote 5 & - & 0,5 \\
Lote 6 & Fusarium sp. \\
\hline
\end{tabular}

Resultados semelhantes também são relatados por JIMÉNEZ et al. (2015), ao avaliarem sementes comerciais de chia. Estes autores evidenciaram a presença dos fungos Penicillium sp., Aspergillus sp., Cladosporium sp., Aspergillus niger, Aspergillus flavus e Curvularia sp. AGUAYSOL et al. (2015), ao avaliarem as doenças no cultivo de chia, nas províncias do Tucumán, evidenciaram a presença de S. sclerotiorum, ocasionando coloração marrom nas inflorescências, podridão da 
haste e formação de escleródios nas inflorescências, pois este patógeno é disseminado via sementes.

GONZÁLES et al. (2010), ao estudarem a espécie Salvia officinalis L. nas províncias de Tucumán e Salta, na Argentina, observaram doenças fitopatogênicas causadas por: Fusarium sp. (murchamento generalizado), Phytophthora sp. (clorose nas folhas), Macrophomina faseolina (manchas negras nas hastes), Rizoctonia solani (necrose nas folhas) e Sclerotinia sclerotiorum (podridão branca).

Sabe-se que os fungos fitopatogênicos podem afetar todas as fases de desenvolvimento das plântulas e que grande parte destes são transmitidos por meio das sementes, podendo até mesmo causar a morte destas. Desta maneira, a doença também pode diminuir a qualidade fisiológica das sementes. Ademais, a disseminação a grandes distâncias pode advir justamente por meio destas sementes contaminadas, que são consideradas fonte de inóculo primária do fungo (OLIVEIRA, 2013).

De acordo com os valores de germinação e IVG (Tabela 2), nota-se que tais lotes possuíram qualidade fisiológica desuniforme, sendo que um deles (lote 5) apresentou valores insuficientes a título de comercialização ( $\geq 80 \%)$. Em contrapartida, RIGUEIRA et al. (2014), ao avaliarem um lote de sementes de chia provenientes de Santa Cruz de La Sierra, Bolívia, constataram que a germinação foi de $100 \%$ e o vigor manteve-se, mesmo 120 dias após armazenamento em diferentes temperaturas.

TABELA 2- Germinação e Índice de velocidade de germinação (IVG) de seis lotes de chia provenientes do município de Pelotas.

\section{Qualidade Fisiológica Sementes de Chia}

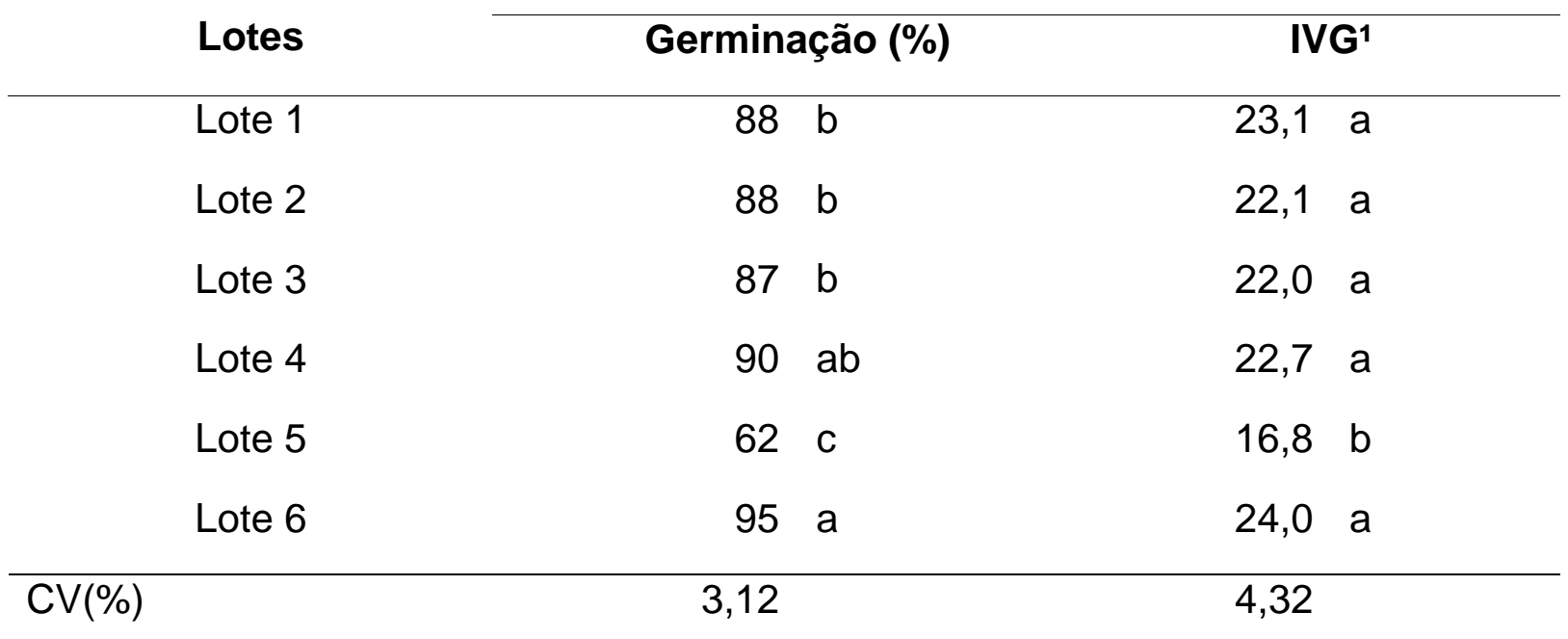

${ }^{1}$ Índice de velocidade de germinação (IVG)

${ }^{2}$ Médias seguidas de mesmas letra minúscula na coluna diferem pelo teste de Tukey $(p \leq 0,05)$.

Este fato revela que alguns lotes de sementes disponíveis no mercado na região de Pelotas não são satisfatórios para fins de cultivo. A competitividade do mercado agrícola busca maior rentabilidade e eficiência produtiva, assim sendo, as informações de germinação e vigor estão intimamente relacionadas a estas questões, já que estas análises traduzem a capacidade máxima dos atributos 
genéticos, físicos, fisiológicos e sanitários das sementes (CARVALHO \& NAKAGAWA, 2000).

A avaliação da qualidade fisiológica de sementes é um aspecto importante a ser considerado em um programa organizado de produção, pois o emprego de metodologia adequada possibilita a estimativa do vigor, do desempenho em campo e o descarte de lotes deficientes, diminuindo riscos e prejuízos (DIAS e FILHO, 1996). Desta maneira, o vigor das sementes exprime o seu nível de qualidade fisiológica está relacionada com uma série de fatores como: condições climáticas durante a maturação, condições de armazenamento, tamanho das sementes, tratamento químico das sementes e nutrição das plantas progenitoras entre outros (CARVALHO \& NAKAGAWA, 2000).

\section{CONCLUSÕES}

Sementes de chia disponíveis no comércio do município de Pelotas-RS apresentam baixa incidência de fungos fitopatogênicos, porém há variação na qualidade fisiológica.

\section{REFERÊNCIAS}

AGUAYSOL, N. C.; TERÁN, L. R.; GONZÁLEZ, V.; ZAVALÍA, R. L.; PLOPER, L. D. Detección de Sclerotinia sclerotiorum en cultivos de chía (Salvia hispánica L.) en Tucumán durante la campaña 2014. Avance Agroindustrial, v. 35, n. 4, p. 20-24, 2014.

BARROCAS, E. N.; MACHADO, J. C. Introdução à patologia de sementes e testes convencionais de sanidade de sementes para a detecção de fungos fitopatogênicos. Informativo Abrates, v. 20, n. 3, p. 74-83. 2010.

BRASIL. Ministério de Agricultura, Pecuária e Abastecimento. Manual de Análise Sanitária de Sementes. Brasília: MAPA/ACS, 2009. 200p.

CAPPELINI, L. T.; PANIZZI, R. C.; VIEIRA, R. D.; GALLI, J. A. Efeito de Fusarium moniliforme na qualidade de sementes de milho. Científica. v. 33, n.2, p. 185-191, 2005.

CARVALHO, N. M.; NAKAGAWA, J. Sementes: Ciência, tecnologia e produção. 4. Ed. FUNEP, 2000. 588p.

COATES, W. Chia: the complete guide to the ultimate superfood. New York: Sterling Publishing Eds., 2012. 192 p.

DIAS, D. FILHO, M. Testes de condutividade elétrica para avaliação do vigor de sementes de soja (Glycine $\max$ (L.) Merrill, Scientia agrícola, v. 53 n. 1., p. 31-42, 1996. em:

http://www.scielo.br/scielo.php?script=sci_arttext\&pid=S0103-90161996000100005> doi: 10.1590/S0103-90161996000100005

GONZÁLEZ, V.; V. MARTíNEZ; L. MUÑOZ Y D. L. PLOPER. Patógenos detectados en el cultivo de chía (Salvia officinalis L.) en las provincias de Tucumán y Salta. Journal Avance Agroindustrial, v. 31, n.4, p. 36-39, 2010. 
JIMÉNEZ, I. A. R.; AYALA, A. G.; AGÜERO, J. M. O.; RÍOS, D. F.; BENÍTEZ, N.; CAZAL, C. C.; MARTíNEZ, L.; MENDES, J. M.; ALVARENGA, A. A. A. Detección e identificación de hongos en semillas de chía/Detection and identification of fungi in seeds of chia. II Jornadas Paraguayas de Botánica - Sesión Micología y Liquenología. Revista Steviana, v. 7, n. 21767, p.87, 2015.

LUCCA FILHO, O. A.; FARIAS, C. R. J. Patologia de sementes. In: PESKE, S. T.; VILLELA, F. A.; MENEGHELLO, G. E. Sementes: fundamentos científicos e tecnológicos. 3 ed. Pelotas, RS. UFPEL, 2012. p-273-369.

MARCOS FILHO, J. Importância do potencial fisiológico da semente de soja. Informativo ABRATES, v. 23, n.1, 2013.

MARTINEZ, M. J.; MARÍN, M, A.; FALLER; C. M. S.; REVOL, J.; PENCI, M. C.; RIBOTTA, P. D. Chia (Salvia hispanica L.) oil extraction; Study of processing parameters. Food Science and Technology, v. 47, p.78-82, 2012. Disponível em: < http://dx.doi.org/10.1016/j.Iwt.2011.12.032>. doi: 10.1016/j.Iwt.2011.12.032

OLIVEIRA, V. A. Use of seed treatment with fungicide in control of Colletotrichum truncatum and physiological quality of soybean seeds Glycine max. Journal of Biotechnology and Biodiversity, v.4, n.2, p.98-106, 2013.

OLIVOS-LUGO, B.; VALDIVIA-LÓPEZ, M. Á; TECANTE, A. Thermal and Physicochemical Properties and Nutritional Value of the Protein Fraction of Mexican Chia Seed (Salvia hispanica L.). Food Science and Technology International, v. 16, n.1, p. 89-96, 2010.

REIS, E. M. Podridão de raízes seminais e lesões foliares do trigo (Triticum aestivum L.) associados à Helminthosporium sativum Pam., King \& Bakke, transmitido pela semente. Summa Phytopathologica, v. 7, n. 3/4, p. 39-44. 1981.

RIGUEIRA R. J. A.; LACERDA FILHO, A. F.; ZAMBIASI, C. A.; MARQUES, K. K. M.; OLIVEIRA FILHO, D. Conservação e armazenamento de chia. In: XLIII Congresso Brasileiro de Engenharia Agrícola - CONBEA, 2014. Campo Grande. Anais. Centro de Convenções "Arquiteto Rubens Gil de Camillo", 2014. Acesso em: 11 abr. 2016. 